\title{
Estandarización y evaluación de dos pruebas de Reacción en Cadena de la Polimerasa para el diagnóstico de Salmonella enterica subespecie enterica en huevos
}

\author{
Standardization of two Polymerase Chain Reaction tests for the diagnosis of \\ Salmonella enterica subspecie enterica in eggs \\ CM Pérez ${ }^{a}$, MM Sánchez ${ }^{b}, S_{\text {Henao }}{ }^{a}$, NM Cardona-Castro ${ }^{* b}$

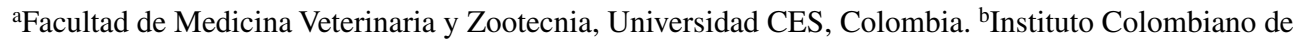 \\ Medicina Tropical, Universidad CES, Colombia.
}

\begin{abstract}
SUMMARY
Salmonella enterica subspecie enterica is an important cause of zoonoses due to its capacity of infecting animals and humans. Poultry and its derivates are sources of transmission, therefore detection becomes an important control measure. Microbiological cultures are currently being used for this purpose but they have sensitivity limitations; molecular alternatives such as PCR allow for a fast and specific detection of Salmonella. The objective of this study was to standardize a PCR for Salmonella in egg samples and a multiplex PCR for Enteritidis and Typhimurium. One hundred and fourty four egg samples were studied: 36 shell wash, 36 yolk-albumen, 36 peptone water plus yolk-albumen, and 36 washes of internal shell. In addition, 24 yolk-albumen samples were infected with 4 different Salmonella serotypes. The DNA from the samples was tested for hilA and multiplex PCR. The PCR for hilA gene showed a sensitivity (S) of $70.83 \%$ and specificity (Sp) of $100 \%$, a positive predictor value (PPV) of $100 \%$, and a negative predictive value (NPV) of $96.3 \%$. The multiplex PCR showed a S of $75 \%$ and a Sp of $98.4 \%$, PPV of $75 \%$, and NPV of $98.4 \%$. Both PCR tests can detect 0.27 $\mu \mathrm{g} / \mathrm{ml}$ of DNA. The results show a potential value of these tests for the detection and control of salmonellosis transmitted by eggs. Further studies are needed in order to improve the sensitivity of detection, so that both tests can be used in the poultry and food industry.
\end{abstract}

Palabras clave: Salmonella, huevos, PCR, diagnóstico.

Key words: Salmonella, eggs, PCR, diagnosis.

\section{INTRODUCCION}

El género Salmonella está compuesto por bacilos Gram negativos productores de salmonelosis, afecta a aves de corral, vacunos, porcinos, ovinos, entre otras especies animales, y al ser humano (Poppe 2000). Estas bacterias son agentes causales de enfermedades transmitidas por alimentos (ETAs) (Humphrey y col 1994). Las fuentes de infección alimentaria más frecuentes para el humano son la carne de pollo y los huevos. Datos estadísticos aportados por distintos países señalan que entre el 50 al $90 \%$ de las carcasas de pollo pueden estar contaminadas con Salmonella (Geornaras y col 1996).

La ausencia de agentes físicos, químicos o biológicos que puedan poner en peligro la salud del consumidor es el aspecto esencial de su calidad y constituye la principal responsabilidad de todo procesador de alimentos (Acha y Szyfres 2001).

La detección de la contaminación de huevos por Salmonella enterica no está aún reglamentada en Colombia

Aceptado: 28.11.2007.

* Instituto Colombiano de Medicina Tropical, Universidad CES, Cra. 43A No 52 Sur 99, Sabaneta, Antioquia, Colombia; ncardona@ces. edu.co debido a los altos costos. Sin embargo, su implementación podría ser una gran ayuda para los productores avícolas, pues garantizaría en los diferentes mercados la calidad del producto que ofrecen.

Salmonella presenta una clasificación compleja. En la actualidad se reconoce la existencia de dos especies, Salmonella enterica y Salmonella bongori, a su vez $S$. enterica se subdivide en seis subespecies: I enterica, II salamae, III arizonae, IV diarizonae, V houtenae y VI indica (Brenner y col 2000).

Salmonella no forma parte de la flora intestinal normal de las aves, éstas la adquieren a partir de insectos, roedores, aves silvestres y el humano. Esta bacteria puede infectar los huevos ya sea por vía transovárica (transferencia vertical) o en el momento de la postura (Mokhtari y col 2006).

Adicionalmente, existen factores predisponentes para la infección y multiplicación de Salmonella en huevos, tales como el contacto con animales infectados, contacto con materia fecal infectada, infección por la ingesta de alimento balanceado contaminado y transporte inadecuado (Haas 1983).

De los serotipos que pueden infectar huevos y aves, $S$. enterica serovar Enteritidis es una de las más importantes por la alta difusión entre los animales y su patogenicidad para el humano. Este serotipo se propaga, principalmente, por transmisión horizontal entre las aves enfermas y en 
menor grado por transmisión vertical a través del huevo a la progenie (Drociuk y col 2003).

En cuanto a datos epidemiológicos de enfermedad producida por Salmonella en humanos, entre 1995 y 1999 fue el segundo agente causal $(35,3 \%)$ de brotes de ETAs en América Latina y el Caribe. Entre 1993 y el 2002 se han registrado en Latinoamérica 1.256 brotes de salmonelosis, estos brotes afectaron 48.334 personas y 15 personas murieron por esta causa.

Según el tipo de alimento consumido, 29,2\% de los casos fueron causados por el consumo de huevos y productos derivados, 9,4\% debido a la ingesta de carne de aves, $9,8 \%$ de los brotes fueron causados por Salmonella Enteritidis y en el $85 \%$ de los casos no se pudo determinar el serotipo implicado ${ }^{1}$.

La detección e identificación de los patógenos implicados en las enfermedades transmisibles es un componente fundamental de la vigilancia epidemiológica $^{2}$. Se hace entonces necesario estandarizar técnicas de detección para implementar la vigilancia y el control de estos microorganismos y prevenir las enfermedades que producen.

Sin embargo, es importante destacar que mediante la aplicación de medidas preventivas en la crianza de las aves y en el procesamiento y manejo comercial de los productos alimenticios y sus derivados, en conjunto con una educación sanitaria de la población para el manejo correcto de los alimentos para su almacenamiento y elaboración, es posible reducir considerablemente el grado de contaminación con Salmonella (Tauxe 1997). Estos datos justifican la necesidad de lograr la rápida detección de Salmonella y otros contaminantes en alimentos.

La detección de contaminación por Salmonella spp. en aves de corral y sus derivados se realiza utilizando métodos convencionales de cultivos microbiológicos, los cuales presentan limitaciones importantes para la detección eficaz de dicha contaminación (St Louis y col 1988). Los métodos clásicos de diagnóstico bacteriológico de Salmonella spp. son laboriosos, requieren tiempo y no todas las cepas aisladas pueden ser identificadas, por lo cual la información que brindan es limitada y dificulta la toma de decisiones. La detección temprana de los microorganismos prevendría la aparición de brotes y permitiría implementar controles previos a la ocurrencia de la enfermedad.

La sensibilidad y especificidad de los métodos de cultivo dependen de la calidad, la toma adecuada de muestras, el almacenamiento y el número de unidades formadoras de colonia (UFC) presentes en la muestra, además de la

1 Sistema Regional de Información para la Vigilancia de las Enfermedades Transmitidas por Alimentos. Sirveta. Consultado en abril 2007, http://www.panalimentos.org/sirveta/e/index.htm

2 Velilla A, Terzolo H, Feingold S. Avances en el diagnóstico molecular de Salmonella. PCR aplicada a la avicultura y a la microbiología de los alimentos. Consultado mayo 10 de 2007, http://www.inta.gov.ar/balcarce/info/documentos/ganaderia/otras/ aves/salmonella.htm. habilidad del microbiólogo para detectar su presencia y la necesidad de un laboratorio de microbiología de alimentos para realizar el proceso (Lammerding y col 2000). A pesar de estas limitaciones, los métodos microbiológicos son los más utilizados por su tradición, ya que no hay disponibles actualmente métodos alternativos que muestren más sensibilidad y especificidad.

Sin embargo, a través del tiempo se han desarrollado métodos más sensibles y específicos que detectan la infección por Salmonella spp. en humanos y que aún no han sido implementados en la industria agropecuaria. Estas alternativas para la detección de contaminación por Salmonella spp. en huevos consisten en la utilización de pruebas de diagnóstico rápidas, sensibles y específicas basadas en métodos de detección molecular (Woodward y Kirwan 1996).

La técnica basada en la reacción en cadena de la polimerasa (Polymerase Chain Reaction o PCR) ha revolucionado el diagnóstico molecular de las enfermedades infecciosas. Este método, a diferencia de los métodos tradicionales que requieren 6 o 7 días para dar un resultado definitivo, permite obtener los resultados en sólo 1 a 3 días, dependiendo de diversas modificaciones en el protocolo de trabajo, permitiendo la detección e identificación rápida y precisa de Salmonella (Myint y col 2006).

Considerando la importancia del tema y la necesidad de la detección rápida de alimentos contaminados, en este trabajo se estandarizó y evaluó la prueba de PCR para detección del género Salmonella, la cual fue previamente estandarizada y evaluada en muestras humanas (Sánchez y Cardona 2004), y la evaluación y estandarización de una PCR múltiple para identificar Salmonella Enteritidis y Salmonella Typhimurium (Soumet y col 1999) en huevos contaminados artificialmente, ya que la detección de este microorganismo por procedimientos cada vez más rápidos y seguros se hace de vital importancia para prevenir brotes de la infección y las consecuencias que ésta acarrea.

\section{MATERIAL Y METODOS}

El tipo de estudio corresponde a Prueba de una prueba, y como Prueba de oro se utilizó el cultivo bacteriológico.

\section{POBLACION}

La muestra para probar sensibilidad (S), especificidad (E), valor predictivo positivo (VPP), valor predictivo negativo (VPN) de la PCR se calculó teniendo como base la prevalencia de salmonelosis en humanos en nuestro medio, pues la prevalencia de infección por $S$. Pullorum, $S$. Enteritidis, $S$. Typhimurium y $S$. Choleraesuis en aves de corral no se conoce. La prevalencia de salmonelosis en humanos en nuestro medio es del $0,01 \%$ (Crump y col 2004), con una confiabilidad del $90 \%$ y un error máximo de 0,05 . 
Para la determinación de la S, E, VPP y VPN de las pruebas se evaluaron dos grupos de muestras distribuidas de la siguiente forma:

Grupo 1: 144 muestras de 36 huevos, 36 muestras de lavado externo de cáscara, 36 muestras de clara-yema, 36 muestras de clara-yema más agua peptonada y 36 muestras de lavado interno de cáscara.

Grupo 2: 24 muestras de clara-yema infectadas con $10^{6}$ $\mathrm{UFC} / \mathrm{ml}$ de 4 serotipos de Salmonella enterica, 6 muestras de clara-yema inoculadas con $S$. Enteritidis, 6 muestras con $S$. Typhimurium, 6 muestras con $S$. Pullorum y 6 muestras con $S$. Choleraesuis.

El cálculo de S, E, VPP y VPN se realizó utilizando la tabla de $2 \times 2$, que compara los resultados de la prueba en las diversas muestras del grupo 1 (muestras no inoculadas) y las del grupo 2 (muestras inoculadas) (Jekel y col 1996). La siguiente ilustración detalla el procedimiento seguido para el cálculo:

\begin{tabular}{|c|c|c|c|}
\hline \multirow{5}{*}{ Resultado de la PCR } & & \multicolumn{2}{|c|}{ Muestras probadas } \\
\hline & \multirow{3}{*}{$\begin{array}{l}\text { Pos } \\
\text { Neg }\end{array}$} & \multicolumn{2}{|c|}{ Inoculadas $\begin{array}{c}\text { No } \\
\text { inoculadas }\end{array}$} \\
\hline & & $\mathrm{a}$ & $\mathrm{b}$ \\
\hline & & $\mathrm{c}$ & d \\
\hline & Total & $a+c$ & $b+d$ \\
\hline
\end{tabular}

$S=a /(a+c)$

$\mathrm{E}=\mathrm{d} /(\mathrm{b}+\mathrm{d})$

$\mathrm{VPP}=\mathrm{a} /(\mathrm{a}+\mathrm{b})$

$\mathrm{VPN}=\mathrm{d} /(\mathrm{c}+\mathrm{d})$

CEPAS

$S$. Enteritidis $459, S$. Typhimurium 138, S. Choleraesuis 86 y $S$. Pullorum 456 (Departamento de Microbiología, Universidad de Harvard); estas cepas se encontraban almacenadas en agar más glicerol a $-20^{\circ} \mathrm{C}$.

\section{OBTENCION DE MUESTRAS}

Los huevos utilizados fueron obtenidos en supermercados de la ciudad.

Lavado de cáscara externa: cada huevo se sumergió individualmente en $250 \mathrm{ml}$ de agua peptonada estéril con el fin de lavar la cáscara externa, se puso en agitación por 15 minutos. Posteriormente, el agua peptonada de este lavado se incubó a $37^{\circ} \mathrm{C}$ por 18 horas.

Clara-yema: se extrajo el huevo del agua peptonada, posteriormente se lavó con agua destilada estéril y con alcohol. Se secó con gasa estéril y se realizó perforación de la cáscara con punzón bajo condiciones estériles. Se extrajo la clara-yema y se homogenizó, se tomaron $5 \mathrm{ml}$ de esta muestra y se incubó a $37^{\circ} \mathrm{C}$ por 18 horas.
Clara-yema más agua peptonada: se extrajo la clara-yema y se homogenizó, se tomaron $5 \mathrm{ml}$ de esta muestra y se inocularon en $45 \mathrm{ml}$ de agua peptonada (relación 1:9), se incubó a $37^{\circ} \mathrm{C}$ por 18 horas.

Lavado de cáscara interna: la cáscara drenada de la clarayema se llenó con agua peptonada, se cubrió con parafilm y se incubó a $37^{\circ} \mathrm{C}$ por 12 a 18 horas.

\section{CULTIVOS}

Después de la primera incubación descrita, cada muestra se repicó en agar Mueller Hinton, agar sangre de carnero, agar MacConkey y XLD (Xilosa Lactosa Dexosicolato) (Beckton Dickinson BD, BBL); estos cultivos se incubaron a $37^{\circ} \mathrm{C}$ hasta el día siguiente.

Todos los aislamientos bacterianos fueron identificados utilizando pruebas de identificación bioquímica como las series bioquímicas y el API 20E (Biomerieux).

\section{INOCULACION ARTIFICIAL}

Las muestras de clara-yema escogidas para inoculación artificial se confirmaron negativas para Salmonella enterica por cultivo y PCR. Se procedió a la inoculación de la clara-yema con un inóculo de $10^{6} \mathrm{UFC} / \mathrm{ml}$. Brevemente, a partir de un cultivo en agar nutritivo incubado por 12-18 horas a $37{ }^{\circ} \mathrm{C}$ de cada uno de los serotipos $S$. Enteritidis, $S$. Typhimurium, $S$. Choleraesuis y $S$. Pullorum, se realizó un inóculo en solución salina estéril y se leyó en espectrofotómetro a una densidad óptica (DO) de $625 \mathrm{~nm}$, se estableció un patrón 0,5 Mc Farland que corresponde a una densidad óptica de 0,08-0,1. La concentración en UFC/ml del inóculo se determinó por ensayo y error hasta estandarizar la lectura ideal para reproducir una infección semejante a la producida. A partir de este inóculo se agregaron $10 \mu \mathrm{l}$ del inóculo a cada muestra de clara-yema.

\section{CONCENTRACION DE DETECCION MINIMA DE ADN}

Para determinar la concentración mínima de ADN que las pruebas de PCR pueden detectar, se realizó infección de muestras de clara-yema con un inóculo conocido y diluciones seriadas de la bacteria a partir de $10^{6} \mathrm{UFC} / \mathrm{ml}$, hasta una dilución de 1:10.000 que equivale a $100 \mathrm{UFC} / \mathrm{ml}$. La concentración en $\mu \mathrm{g} / \mathrm{ml}$ de ADN se determinó por lectura en espectrofotómetro a 260 y 280 $\mathrm{nm}$ y las UFC/ml por cultivo en agar XLD.

\section{PCR PARA GEN HILA Y PCR MULTIPLE}

La extracción de ADN se realizó a todas las muestras de lavado de cáscara externa, clara-yema, lavado de cáscara interna y clara-yema inoculada; se utilizó el protocolo de buffer de lisis modificado, descrito por Haque y col (1999). Brevemente, $1 \mathrm{ml}$ de cada muestra se centrifugó a 10.000 
rpm por cinco minutos a temperatura ambiente para separar la muestra del agua peptonada. Un $\mathrm{ml}$ de buffer de lisis $(0,2 \%$ Triton X100 en Tris HCL mas EDTA pH 8,0) se adicionó al sedimento. La mezcla se aspiró varias veces y se centrifugó a $12.000 \mathrm{rpm}$ a temperatura ambiente por seis minutos, el sobrenadante se descartó y el procedimiento se repitió. El sedimento se lavó con agua destilada y se centrifugó a 12.000 rpm a temperatura ambiente por 1 minuto. El sobrenadante se descartó y el sedimento se resuspendió en $50 \mu \mathrm{l}$ de agua destilada ultrapura estéril. Los tubos se sellaron y se sometieron a ebullición por 20 minutos y se dejaron enfriar a temperatura ambiente antes de realizar la PCR.

\section{INICIADORES}

En el cuadro 1 se pueden observar las secuencias de los iniciadores que se utilizaron en el presente estudio y el tamaño de los productos de amplificación.

\section{CONDICIONES DE AMPLIFICACION}

Para la amplificación del gen hilA se utilizó el protocolo descrito por Sánchez y Cardona (2004), para la PCR múltiple se utilizó el protocolo descrito por Soumet y col (1999). Para ambas reacciones de amplificación se utilizaron las siguientes cantidades de reactivos: $1 \mu 1$ del cebador 5' -3' en una concentración de $10 \mu \mathrm{M}, 1 \mu \mathrm{l}$ del cebador 3' -5' en una concentración $10 \mu \mathrm{M}, 1 \mu 110 \mathrm{mM}$ de la mezcla de los desoxinucleótidos, $5 \mu \mathrm{l}$ de buffer 10X, 0,5 $\mu \mathrm{l}$ de Taq polimerasa (Invitrogen) en una concentración de $5 \mathrm{U} / \mu \mathrm{l}$, $21,5 \mu \mathrm{l}$ de agua destilada estéril y $10 \mu \mathrm{l}$ de $\mathrm{ADN}$, para un volumen final de reacción de $40 \mu \mathrm{l}$. La temperatura de alineamiento utilizada fue $65^{\circ} \mathrm{C}$ para hilA y $55^{\circ} \mathrm{C}$ para la PCR múltiple. Cada muestra se amplificó por duplicado. Se procesaron adicionalmente un control positivo (Salmonella enterica ATCC) y dos controles negativos.

\section{DETECCION DE PRODUCTOS DE AMPLIFICACION}

En $100 \mathrm{ml}$ de gel de agarosa al $1 \%$ conteniendo $10 \mu \mathrm{l}$ de SYBR SAFE® (10.000 x) (Invitrogen), se fraccionaron electroforéticamente $12 \mu \mathrm{l}$ del producto de amplificación.
En cada gel se corrieron adicionalmente el control positivo y dos controles negativos. En la figura 1 se observa detalladamente el procedimiento realizado con cada huevo.

\section{RESULTADOS}

\section{GRUPO 1 (MUESTRAS NO INOCULADAS)}

Las muestras de los huevos no inoculados fueron negativas por cultivo y PCR para Salmonella, significando esto que no estaban infectadas de origen con la bacteria.

Sin embargo, estas muestras sí fueron positivas para otras bacterias potencialmente patógenas según reportes previos como Escherichia coli. El cuadro 2 muestra las bacterias aisladas de las muestras de huevos no inoculados con Salmonella.

\section{GRUPO 2 (MUESTRAS INOCULADAS CON SALMONELLA)}

Cultivos: luego de la inoculación de clara-yema con un inóculo conocido, se realizó cultivo; éste siempre fue positivo para el serotipo inoculado, confirmando la viabilidad del inóculo de Salmonella spp.

PCR: a partir de las muestras inoculadas con $10^{6} \mathrm{UFC} / \mathrm{ml}$, en la PCR para el gen hilA, se obtuvieron los resultados que se pueden observar en el cuadro 3.

El análisis de estos resultados muestra que para un inóculo de $10^{6}$ la PCR específica de género mostró sensibilidad (S) $70,83 \%$, especificidad (E) $100 \%$, valor predictivo positivo (VPP) $100 \%$ y valor predictivo negativo (VPN) 96,3\%. La cantidad mínima de ADN que la prueba de PCR para el gen hilA puede detectar es de $0,027 \mu \mathrm{g} / \mathrm{ml}$, lo que corresponde a $100 \mathrm{UFC} / \mathrm{ml}$. En la figura 2 se puede observar la prueba de sensibilidad de detección mínima, utilizando diluciones seriadas de ADN. En la figura 3 se observa un gel con muestras positivas y negativas para el gen hilA.

PCR múltiple: a partir de las muestras inoculadas con $10^{6}$ $\mathrm{UFC} / \mathrm{ml}$, en la PCR múltiple se obtuvieron los resultados que se aprecian en el cuadro 3. El análisis de estos resultados mostró que la PCR múltiple tiene sensibilidad del

Cuadro 1. Secuencias de los iniciadores y tamaño de los productos de amplificación. Sequences of primers and size of amplification product.

\begin{tabular}{llc}
\hline \multicolumn{1}{c}{ Iniciador } & \multicolumn{1}{c}{ Secuencia } & Producto de amplificación \\
\hline hilA US (género) & 5'-GCATGGATCCCCGCCGGCGAGATTGTG-3' & \multirow{2}{*}{$854 \mathrm{pb}$} \\
hilA DS & 5'-CGGAAGCTTATTTGCGCCATGCTGAGGTAG-3' & \\
Sef167 (PCR Múltiple) & 5'-AGGTTCAGGCAGCGGTTACT-3' & \multirow{2}{*}{$312 \mathrm{pb}$} \\
Sef478 & 5'-GGGACATTTAGCGTTTCTTG-3' & \\
fli15 (PCR Múltiple) & 5'-CGGGTGTGCCCAGGTTGGTAAT-3' & $559 \mathrm{pb}$ \\
Tym & 5'-ACTCTTGCTGGCGGTGCGACTT-3' & \\
\hline
\end{tabular}




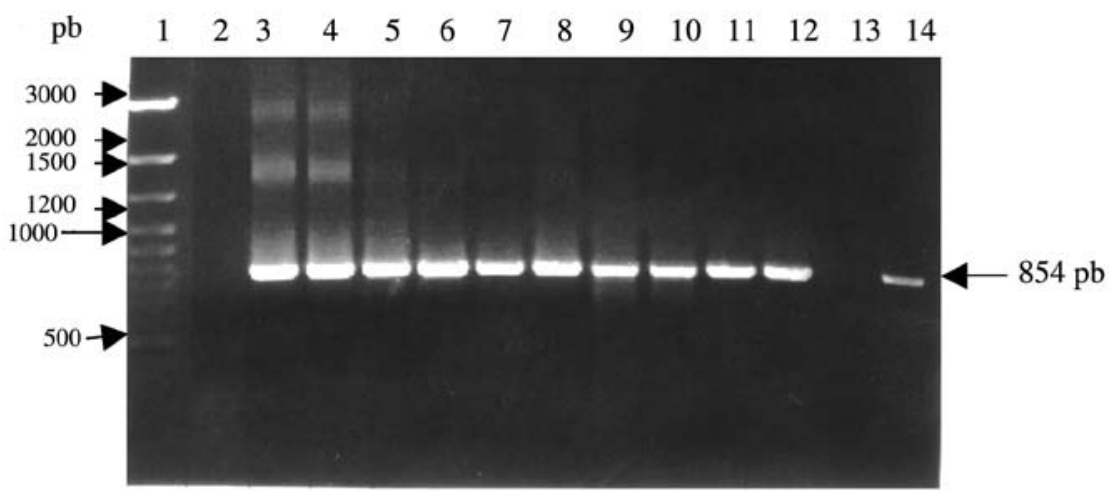

Figura 1. Prueba de detección mínima de ADN por la PCR para el gen hilA. Minimum quantity of DNA detected by hilA gene PCR.

Carril 1 Marcador de tamaño molecular GeneRuler 100 bp ADN Ladder plus (Fermentas); 2 y 13 Control negativo; 3 y 4: 0,377 $\mu \mathrm{g} / \mathrm{ml}$ de ADN de Salmonella; 5 y 6: 0,287 $\mu \mathrm{g} / \mathrm{ml}$ de ADN de Salmonella; 7 y 8 : $0,117 \mu \mathrm{g} / \mathrm{ml}$ de ADN de Salmonella; 9 y 10: 0,063 $\mu \mathrm{g} / \mathrm{ml}$ de ADN de Salmonella; 11 y 12: 0,027 $\mu \mathrm{g} / \mathrm{ml}$ de ADN de Salmonella; 14: Control positivo: ADN de Salmonella Typhimurium 14028.

Line 1 GeneRuler 100 bp ADN Ladder plus (Fermentas); 2 and 13 negative control; 3 and 4: 0.377 $\mu \mathrm{g} / \mathrm{ml}$ of Salmonella DNA; 5 and 6: $0.287 \mu \mathrm{g} / \mathrm{ml}$ of Salmonella DNA; 7 and 8: $0.117 \mu \mathrm{g} / \mathrm{ml}$ of Salmonella DNA; 9 and 10: $0.063 \mu \mathrm{g} / \mathrm{ml}$ of Salmonella DNA; 11 and 12: $0.027 \mu \mathrm{g} / \mathrm{ml}$ of Salmonella DNA; 14 positive control: DNA of Salmonella Typhimurium strain 14028.

Cuadro 2. Bacterias aisladas de las muestras de huevos no inoculados con Salmonella. Bacteria isolates of egg samples non inoculated with Salmonella.

\begin{tabular}{lcccc}
\hline \multicolumn{1}{c}{ Bacterias aisladas } & $\begin{array}{c}\text { Lavado cáscara } \\
\text { externa }\end{array}$ & Clara-yema & $\begin{array}{c}\text { Clara-yema } \mathrm{H}_{2} \mathrm{O} \\
\text { peptonada }\end{array}$ & $\begin{array}{c}\text { Lavado cáscara } \\
\text { interna }\end{array}$ \\
\hline Bacillus & 2 & 10 & 12 & 4 \\
Bacillus + Klebsiella & 1 & 0 & 0 & 0 \\
Bacillus + sarcinas & 1 & 0 & 0 & 0 \\
BGN no fermentadores & 2 & 0 & 6 & 0 \\
Bacillus + BGN & 0 & 0 & 0 & 5 \\
E. coli & 1 & 0 & 0 & 1 \\
Proteus & 1 & 0 & 0 & 7 \\
Pseudomonas & 7 & 1 & 5 & 1 \\
Citrobacter diversus & 0 & 0 & 0 & 18 \\
Sin dato & 18 & 0 & 0 & 4 \\
Negativos & 3 & 25 & 13 & 36 \\
\hline Total general & 36 & 36 & 36 & \\
\hline
\end{tabular}

Cuadro 3. Resultados de PCR múltiple y PCR para el gen hilA en muestras de huevo inoculadas con Salmonella. Multiplex and hilA gene PCR in inoculated egg samples with Salmonella.

\begin{tabular}{|c|c|c|c|c|c|}
\hline \multirow{2}{*}{ Serotipo } & \multicolumn{2}{|c|}{ PCR Múltiple } & \multicolumn{2}{|c|}{ PCR hilA } & \multirow{2}{*}{ Tota } \\
\hline & Neg. & Pos. & Neg. & Pos. & \\
\hline Choleraesuis & 3 & 3 & 3 & 3 & 12 \\
\hline Enteritidis & 2 & 4 & 2 & 4 & 12 \\
\hline Pullorum & 6 & 0 & 2 & 4 & 12 \\
\hline Typhimurium & 1 & 5 & 0 & 6 & 12 \\
\hline Total general & 12 & 12 & 7 & 17 & 48 \\
\hline
\end{tabular}




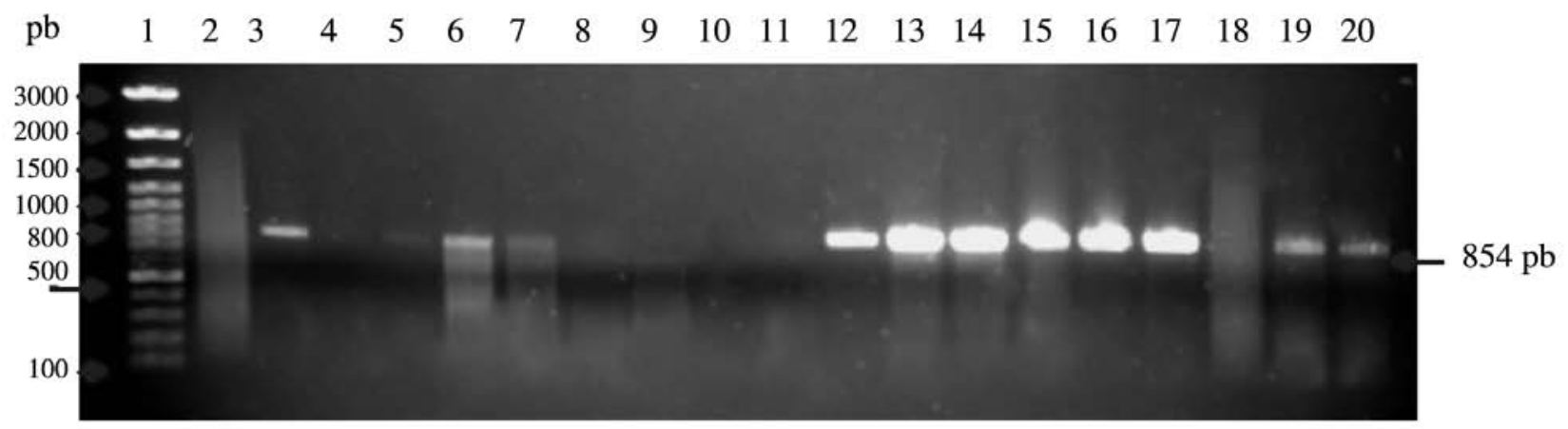

Figura 2. Detección del gen hilA por PCR en muestras de huevo inoculadas con Salmonella spp.

Detection of hilA gene by PCR in Salmonella spp inoculated egg samples.

Carril 1 Marcador de tamaño molecular GeneRuler 100 bp ADN Ladder plus (Fermentas). Carriles 2 y 18 control negativo; 3, 5, 6, 7, 12, 13, 14, 15, 16 y 17: muestras de huevo infectadas con Salmonella serovariedades Enteritidis, Typhimurium, Pullorum y Choleraesuis positivas para el gen hilA; en 4, $8,9,10$ y 11 muestras negativas para el gen hilA; en 19 y 20 Control positivo S. Typhimurium cepa ATCC 14028.

Line 1 GeneRuler 100 bp ADN Ladder plus (Fermentas). Lines 2 and 18 negative control; 3, 5, 6, 7, 12, 13, 14, 15, 16 and 17: egg samples infected with Salmonella serovars Enteritidis, Typhimurium, Pullorum and Choleraesuis, all of them positive for hilA gene; lines 4, 8, 9, 10 and 11 negative samples for hilA gene; lines 19 and 20 positive control S. Typhimurium strain ATCC 14028.

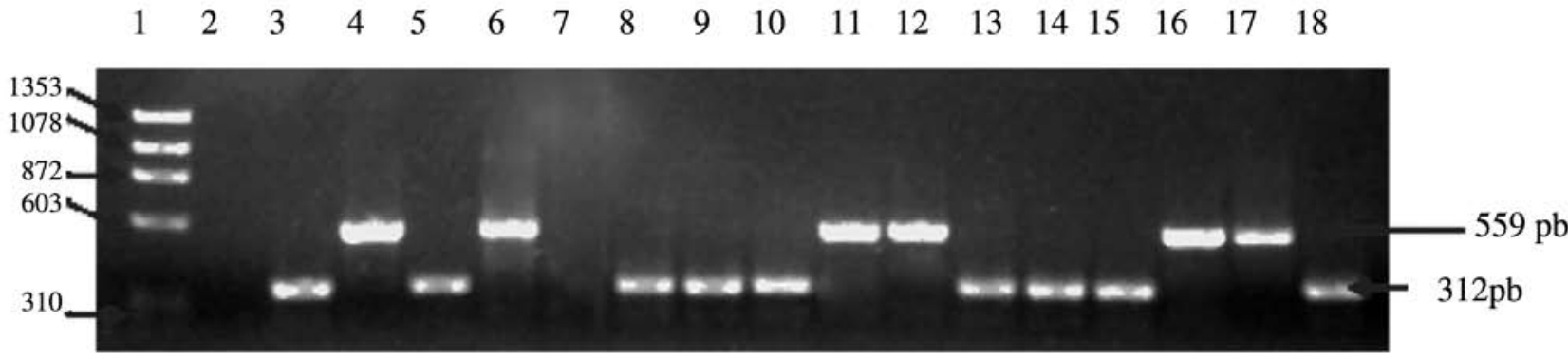

Figura 3. PCR múltiple para la identificación de Salmonella serovariedades Enteritidis y Typhimurium en muestras de huevo inoculadas.

Multiplex PCR for identification of Salmonella serovars Enteritidis and Typhimurium in inoculated egg samples.

Carril 1 Marcador de tamaño molecular $\emptyset$ X 174 Hind III (Promega); 2 control negativo; 3, 5, 7,8, 9, 10, 13, 14 y 15: muestras de huevo infectadas con Salmonella serovariedad Enteritidis; 4, 6, 11, 12, 16 muestras de huevo infectadas con Salmonella serovariedad Typhimurium; 17: Control positivo S. Typhimurium cepa ATCC 14028; 18: Control positivo $S$. Enteritidis.

Prueba de sensibilidad: en la prueba de sensibilidad los inóculos evaluados presentaron las siguientes densidades ópticas: 0,377 (20.000 UFC/ml), 0,117 (10.000 UFC/ml), 0,063 (1.800 UFC/ml) y 0,027 (500 UFC/ml).

Line 1 Gene ruler Ladder $\varnothing$ X 174 Hind III (Promega); line 2 negative control; lines 3, 5, 7,8, 9, 10, 13, 14 and 15: egg samples infected with Salmonella serovar Enteritidis; lines 4, 6, 11, 12, 16 egg samples infected with Salmonella serovar Typhimurium; line 17 positive control DNA of S. Typhimurium strain ATCC 14028; 18 positive control DNA of $S$. Enteritidis

Test of sensibility: the inoculums evaluated showed the follow optic densities: 0.377 (20.000 CFU/ml), $0.117(10,000 \mathrm{CFU} / \mathrm{ml}), 0.063$ (1,800 CFU/ $\mathrm{ml})$, and $0.027(500 \mathrm{CFU} / \mathrm{ml})$.

$75 \%$, especificidad del 98,4\%, VPP del 75\% y VPN del $98,4 \%$. En la figura 3 se puede observar un gel de la PCR múltiple para la identificación de Salmonella serovariedades Enteritidis y Typhimurium.

\section{DISCUSION}

Los resultados obtenidos en este trabajo nos permiten inferir la importancia de utilizar técnicas seguras para obtener derivados alimenticios y en especial los huevos, pues estos son portadores de bacterias encontradas en el tracto digestivo de las gallinas y de otras fuentes de contaminación, las cuales pueden ser agentes patógenos para humanos (Geornaras y col 1996).

La ausencia de Salmonella en los huevos sin contaminar evaluados puede evidenciar el adecuado manejo de éstos por parte de las avícolas y los distribuidores, pero cabe anotar que este estudio no realizó un muestreo en diferentes sitios y por lo tanto esto no se puede inferir para todos los distribuidores. 
Los resultados negativos de las PCR en los huevos inoculados con alguno de los 4 serotipos de Salmonella se pueden deber a la presencia de interferentes de la amplificación de ADN en la muestra, como puede ser el exceso de proteínas, por lo cual se debe realizar en futuros estudios un método de extracción más específico que involucre un paso inicial de desnaturalización de proteínas y que permita que sólo quede el ADN de Salmonella (Woodward y Kirwan 1996).

Detectamos contaminación de origen de partes internas del huevo (clara-yema y cáscara interna) con bacterias que pueden ser patógenos potenciales para humanos, como Escherichia coli y Bacillus (Acha y Szyfres 2001), hallazgo que pone de manifiesto la necesidad e importancia de lavar los huevos inmediatamente antes de consumir con abundante agua y jabón y prepararlos a altas temperaturas para eliminar estos microorganismos.

En los huevos en los cuales no se encontraron microorganismos contaminantes se evidencia un adecuado manejo por parte de las avícolas y distribuidores y probablemente con el tiempo de distribución del producto transcurrido desde la postura, pues los huevos más jóvenes tienen menor probabilidad de contaminarse con bacterias.

En cuanto la sensibilidad de ambas pruebas de PCR, ésta oscila entre el 70 y $75 \%$ este resultado puede deberse a que la extracción del ADN se realizó con un método simple de lisis, en el cual no se usó la purificación del ADN, factor que puede estar afectando la sensibilidad de las pruebas. Estos resultados de sensibilidad pueden mejorarse modificando el método de extracción, incluyendo un paso de purificación del ADN o utilizando un método comercial de extracción, pues las muestras de clara-yema tienen alto contenido proteico que puede interferir en la PCR.

Sin embargo, la sensibilidad alcanzada con la estandarización de estas pruebas de PCR es más alta que la que se obtiene con cultivos convencionales, los cuales alcanzan una sensibilidad variable que puede fluctuar desde el $0-100 \%$ de acuerdo a varios factores, como la viabilidad de las bacterias que se encuentran en la muestra y la recolección y transporte de la misma. Esto significa que la PCR no requiere de la existencia de bacterias vivas o viables en la muestra para diagnosticar una contaminación o infección (Sánchez y Cardona 2004).

La utilidad de la prueba de PCR para detección del gen hilA está basada en la posibilidad de utilizarla para detectar contaminación por el género Salmonella en huevos y otras muestras (Sánchez y Cardona 2004). La PCR múltiple confirma si esta bacteria pertenece al serovar Typhimurium o Enteritidis, arrojando una mayor información si se precisa la identificación por serotipo (Soumet y col 1999).

La especificidad de la PCR múltiple es de $98,4 \%$ y la del gen hilA de un $100 \%$; ambas especificidades son adecuadas para confiar que el resultado es verdadero, siendo la PCR para hilA $100 \%$ específica de género, lo cual tiene ventajas al momento de hacer un diagnóstico de contaminación de huevos por esta bacteria.

La utilización de estas pruebas de PCR permitirá hacer una verificación y control de la salmonelosis. Por su rapidez y precisión, ésta será una herramienta fundamental para lograr la comercialización internacional de huevos, cumpliendo una de las normas de control sanitario exigidas para tal fin ${ }^{3}$.

Este trabajo presenta gran potencial diagnóstico y epidemiológico para la detección y control de las salmonelosis transmitidas por huevos. Se requieren estudios adicionales para aumentar la sensibilidad de las pruebas y su aplicación en el campo avícola y de la industria alimenticia.

Este trabajo se convierte en el punto de partida para realizar más investigaciones para profundizar en el tema. A futuro se planea desarrollar un estudio de aplicación de estas pruebas en un mayor número de muestras de diferentes distribuidoras de la ciudad, mejorando procedimientos como la extracción y purificación de ADN.

\section{RESUMEN}

Salmonella infecta animales y humanos, siendo las aves de corral y sus derivados fuentes de transmisión; por lo tanto, la detección de Salmonella es importante para evitar infección. Los cultivos microbiológicos son usados para identificar la bacteria pero presentan limitaciones, por esto se han desarrollado alternativas moleculares como la Reacción en Cadena de la Polimerasa (PCR), para detectar rápida y específicamente Salmonella. El objetivo de este trabajo fue estandarizar en huevos una PCR para el género Salmonella y una PCR múltiple para S. Enteritidis y S. Typhimurium. Se estudiaron 144 muestras de huevos: 36 lavados de cáscara externa, 36 de clara-yema, 36 clara-yema más agua peptonada y 36 lavados de cáscara interna. Adicionalmente, 24 muestras de clara-yema fueron infectadas independientemente con 4 serotipos de Salmonella. A todas las muestras se les realizó extracción de ADN, PCR para el gen hilA y PCR múltiple. Para el inóculo de $10^{6}$ UFC/ml, la PCR para hilA mostró una sensibilidad de 70,83\% y una especificidad de $100 \%$. Para la PCR múltiple se obtuvo una sensibilidad de $75 \%$ y una especificidad de $98,4 \%$. Ambas pruebas de PCR pueden detectar $0,27 \mu \mathrm{g} / \mathrm{ml}$ de ADN. Estas pruebas presentan gran potencial para detectar y controlar las salmonelosis transmitidas por huevos. Se requieren estudios adicionales para aumentar la sensibilidad y aplicarlas en el campo avícola e industria alimenticia.

\section{AGRADECIMIENTOS}

Este proyecto fue financiado por la División de Investigaciones de la Universidad CES, Facultad de Medicina Veterinaria y Zootecnia-CES, y por el Instituto Colombiano de Medicina Tropical - CES.

3 Velilla A, Terzolo H, Feingold S. Avances en el diagnóstico molecular de Salmonella. PCR aplicada a la avicultura y a la microbiología de los alimentos. Consultado mayo 10 de 2007, http://www.inta.gov. $\mathrm{ar} /$ balcarce/info/documentos/ganaderia/otras/aves/salmonella.htm 


\section{REFERENCIAS}

Acha P, B Szyfres. 2001. Zoonosis y enfermedades transmisibles comunes al hombre y a los animales. $3^{\mathrm{a}}$ ed. OPS. Washington, EE.UU., Pp 28-52.

Brenner FW, RG Villar, FJ Angulo, R Tauxe, B Swaminathan. 2000. Salmonella Nomenclature. J Clin Microbiol 38, 2465-2467.

Cardona-Castro N, E Restrepo-Pineda, M Correa-Ochoa. 2002. Detection of hilA gene sequences in Serovars of Salmonella enterica Subspecies enterica. Mem I Oswaldo Cruz 97, 1153-1156.

Cockerill FR, TF Smith. 2002. Rapid-cycle PCR real-cheats: to revolution for clinical microbiology. ASM News 68, 77-83.

Crump JA, SP Luby, ED Mintz. 2004.The global burden of typhoid fever. Bull World Health Org 82, 346-353.

Drociuk D, S Carnesale, G Elliot, LJ Bell, JJ Gibson, L Wolf, D Briggs, B Jenkins, JM Maillard, M Huddle, F Virgin, C Braden, P Srikantiah, A Stoica, T Chiller. 2003. Outbreaks of Salmonella serotype enteritidis infection associated with eating shell eggs-United States, 1999-2001. MMWR Morb Mortal Wkly Rep 51, 1149-1152.

Geornaras I, AE de Jesús, E Van Zyl, A Von Holy. 1996. Bacterial populations associated with poultry processing in a South African abattoir. Food Microbiol 13, 457-465.

Haas CN. 1983. Estimation of risk due to low doses of microorganisms: a comparison of 2 alternative methodologies. Am J Epidemiol 118, 573-582.

Haque A, J Ahmed, J Qureshi. 1999. Early detection of typhoid by polymerase chain reaction. Ann Saudi Med 7, 337-340.

Humphrey TJ, KW Martin, A Whitehead. 1994. Contamination of hands and work surfaces with Salmonella Enteritidis PT4 during the preparation of egg dishes. Epidemiol Infect 113, 403-409.

Izat A, C Druggers, M Colberg, M Reiber, M Adams. 1989. Comparison of the DNA probe to culture methods for the detection of Salmonella on poultry carcasses and processing waters. J Food Protect 52, 564-570.

Jekel J, J Elmore, D Katz. 1996. Studying the accuracy and usefulness of screening and diagnostic tests. In: Epidemiology Biostatistics and Preventive Medicine. Saunders Company, USA, Pp 87-91.
Lammerding AM, A Fazil. 2000. Hazard identification and exposure assessment for microbial food safety risk assessment. Int $J$ Food Microbiol 58, 147-57.

Mokhtari A, CM Moore, H Yang, LA Jaykus, R Morales, SC Cates, P Cowen. 2006. Consumer-phase Salmonella enterica serovar Enteritidis risk assessment for egg-containing food products. Risk anal 26, 753-768.

Morales RA, RM McDowell. 1999. Economic consequences of Salmonella enterica serovar Enteritidis infection in humans and the U.S. egg industry. In: Saeed AM, Gast RK, Potter ME, Wall PG (eds). Salmonella enterica serovar Enteritidis in humans and animals. Ames Press, Iowa State University, USA, Pp 271-290.

Myint MS, YJ Johnson, NL Tablante, RA Heckert. 2006. The effect of pre-enrichment protocol on the sensitivity and specificity of PCR for detection of naturally contaminated Salmonella in raw poultry compared to conventional culture. Food Microbiol 23, 599-604.

Poppe C. 2000. Salmonella infections in the domestic fowl. In: Wray C, Wray A (eds). Salmonella in Domestic Animals. CAB International, New York, USA, Pp 107-132.

Sánchez Jiménez MM, NM Cardona Castro. 2004. Validation of a PCR for diagnosis of typhoid fever and salmonellosis by amplification of the hilA gene in clinical samples from Colombian patients. $J$ Med Microbiol 53, 875- 878 .

Soumet C, G Ermel, V Rose, N Rose, P Drouin, G Salvat, P Colin.1999. Identification by a multiplex PCR-based assay of Salmonella typhimurium and Salmonella enteritidis strains from environmental swabs of poultry houses. Lett Appl Microbiol 29, 1-6.

St Louis ME, DL Morse, ME Potter, TM DeMelfi, JJ Guzewich, RV Tauxe, PA Blake. 1988. The Emergence of grade A eggs as a major source of Salmonella Enteritidis infections: new implications for the control of salmonellosis. J Am Med Assoc 259, 2103-2107.

Tauxe RV. 1997. Emerging food borne diseases and involving public health challenge. Emerg Infect Dis 4, 425-434.

Woodward MJ, SES Kirwan.1996. Detection of Salmonella enteritidis in eggs by the polymerase chain reaction. Vet Rec 138, 411-413. 